\title{
Oxymatrine induces nasopharyngeal cancer cell death through inhibition of PI3K/AKT and NF-кB pathways
}

\author{
ZHILI NI $^{1}$ and JINGMEI YI ${ }^{2}$ \\ ${ }^{1}$ Department of Otorhinolaryngology Head and Neck Surgery, Xuanwu Hospital, Capital Medical University, \\ Beijing 100053; ${ }^{2}$ Department of Paediatrics, Chinese PLA General Hospital, Beijing 100853, P.R. China
}

Received October 22, 2016; Accepted July 26, 2017

DOI: $10.3892 / \mathrm{mmr} .2017 .7822$

\begin{abstract}
Oxymatrine may inhibit tumor cell proliferation, induce cell cycle arrest, promote apoptosis, induce tumor cell differentiation and fight against tumor angiogenesis, as well as inhibit tumor invasion and metastasis. The present study aimed to investigate the anticancer effects of oxymatrine on nasopharyngeal cancer (NPC) cell death, and the underlying molecular mechanisms of these effects. NPC HK-1 cells were incubated overnight and treated with oxymatrine $(0,2,4,6$ and $8 \mathrm{mg} / \mathrm{ml}$ ) for 1,2 or 3 days. The results demonstrated that oxymatrine significantly inhibited NPC cell proliferation in a time- and dose-dependent manner. Oxymatrine treatment also induced apoptosis, induced the activities of caspase-3 and caspase- 9 , promoted $\mathrm{p} 53$ and Bax protein expression, and suppressed cyclin D protein expression in these cells. The protein expression levels of phosphoinositide 3 kinase (PI3K), phosphorylated (p)-AKT, p-mammalian target of rapamycin, p-p70 ribosomal protein S6 kinase and nuclear factor (NF)- $\mathrm{kB}$ were significantly downregulated by oxymatrine treatment. In conclusion, results from the present study suggested that oxymatrine may induce NPC cell death through the inhibition of PI3K/AKT and NF- $\mathrm{KB}$ signaling pathways.
\end{abstract}

\section{Introduction}

Nasopharyngeal carcinoma (NPC) is a malignant tumor that occurs in epithelial cells of the nasopharynx and is closely related to Epstein-Barr virus infection, with an annual incidence rate of 10-50 out of 100,000 worldwide (1). It is rare in most regions of the world, and its annual incidence rate is only $0.5-0.6$ out of 100,000 in Europe and the United States. The 5-year overall survival of NPC is $84 \%$ of non-metastatic

Correspondence to: Dr Jingmei Yi, Department of Paediatrics, Chinese PLA General Hospital, 28 Fuxing Road, Beijing 100853, P.R. China

E-mail: jiuruimpqc@163.com

Key words: oxymatrine, nasopharyngeal cancer, phosphoinositide 3 kinase/AKT, nuclear factor- $\kappa \mathrm{B}$ cases with intensity-modulated radiation therapy (IMRT) and optimal chemotherapy $(2,3)$.

Recently, the phosphoinositide 3 kinase (PI3K)/AKT signaling transduction pathway has attracted increasing attention (4). Previous studies have reported that the PI3K/AKT signaling pathway is important in the signal transduction of various growth factors, and is closely related to cellular physiological functions as well as the incidence and development of certain tumors $(5,6)$. The products of PI3K 3 -phosphoinositide, that is 3,4-diphosphoinositide and 3,4,5-inositol triphosphate, bind to the PH domain of AKT and induce a conformational change and the subsequent phosphorylation and activation of AKT, which migrates from the cytoplasm to the cell membrane, where it directly or indirectly activates its downstream molecule proteins, such as mammalian target of rapamycin (mTOR), p70 ribosomal protein S6 kinase (p70S6K), matrix metalloproteinase (MMP)-2, and nuclear factor- $\mathrm{\kappa B}$ (NF- $\mathrm{\kappa B}$ ) and insulin-like growth factor I receptor (IGF-IR) (7). The activation of mTOR and p70S6K initiates protein translation to promote protein synthesis; the activation of NF- $\mathrm{KB}$ promotes the transcription of apoptosis-inhibiting genes and upregulates the mRNA and protein expression of IGF-IR and MMP2, thus promoting the invasion and metastasis of cancer cells (8). Therefore, the PI3K/AKT signaling pathway may be considered to serve an important role in cell proliferation, differentiation and migration.

The NF- $\kappa \mathrm{B}$ family of transcription factors promotes tumorigenesis, and functional proteins encoded by NF- $\mathrm{KB}$ may promote tumor growth; NF- $\mathrm{kB}$ may promote tumorigenesis by inhibiting apoptosis (9). NF- $\kappa B$ is inactive in patients with head and neck squamous carcinoma, and inhibiting RelA can increase apoptosis in tumor cells (10). NF- $\mathrm{kB}$ may be an important indicator in the early diagnosis and treatment of tumors (10).

Oxymatrine is a compound (Fig. 1) extracted from radix sophorae flavescentis that has been previously reported to exhibit antitumoral effects, mainly by inhibiting the differentiation and apoptosis of tumor cells, suppressing the proliferation and metastasis of tumor cells, inhibiting the activity of telomerase, suppressing tumor angiogenesis, inhibiting drug resistance of tumor and promoting antitumor immune response of the host $(11,12)$. The present study investigated the anticancer effects of oxymatrine on NPC cell death and the underlying molecular mechanisms of these effects. 


\section{Materials and methods}

Cell culture. The human NPC HK-1 cell line was obtained from the Experimental Center of Capital Medical University (Beijing, China) and cells were maintained in RPMI-1640 medium (Invitrogen; Thermo Fisher Scientific, Inc., Waltham, MA, USA) containing 10\% fetal bovine serum (Invitrogen; Thermo Fisher Scientific, Inc.), $100 \mathrm{U} / \mathrm{ml}$ penicillin and $100 \mathrm{mg} / \mathrm{ml}$ streptomycin in a humidified atmosphere containing $5 \% \mathrm{CO}_{2}$ at $37^{\circ} \mathrm{C}$.

Cell proliferation assay. HK-1 cells were seeded (1,000 cells/well) into 96-well plates, incubated overnight and treated with oxymatrine $(0,2,4,6$ and $8 \mathrm{mg} / \mathrm{ml}$; Sigma-Aldrich; Merck KGaA, Darmstadt, Germany) for 1,2 and 3 days at $37^{\circ} \mathrm{C}$. MTT (10 ml; $5 \mathrm{mg} / \mathrm{ml}$; Beyotime Institute of Biotechnology, Haimen, China) was added and was incubated in darkness for $4 \mathrm{~h}$ at $37^{\circ} \mathrm{C}$. The media was removed and dimethylsulfoxide was added to dissolve the formazan crystals for $20 \mathrm{~min}$; the absorbance was measured using a FluoDia T70 microplate reader (Photon Technology International, Inc.; Horiba, Ltd., Stanmore, UK) at a wavelength of $490 \mathrm{~nm}$.

Flow cytometric analysis. HK-1 cells were seeded (1-2x10 $0^{5}$ cells/well) into 6-well plates, incubated overnight and treated with oxymatrine $(0,4,6$ and $8 \mathrm{mg} / \mathrm{ml})$ for 2 days. Cells were centrifuged at $1,000 \mathrm{x}$ g at $4^{\circ} \mathrm{C}$ for $10 \mathrm{~min}$ and washed using PBS three times. Cells were stained using an Annexin V-fluorescein isothiocyanate (FITC)/propidium iodide (PI) Cell Apoptosis Detection kit (BD Biosciences, Franklin Lakes, NJ, USA) according to the manufacturer's protocols, and fluorescence was determined using a FACSCalibur flow cytometer (BD Biosciences) and analyzed using Flowjo version 7.6.1 (FlowJo LLC, Ashland, OR, USA).

Caspase-3 and caspase-9 activities. HK-1 cells were seeded $\left(1-2 \times 10^{5}\right.$ cells/well) into 6 -well plates, incubated overnight and treated with oxymatrine $(0,4,6$ and $8 \mathrm{mg} / \mathrm{ml})$ for 2 days at $37^{\circ} \mathrm{C}$. Cell protein extracts were prepared in radioimmunoprecipitation assay (RIPA) buffer (Beyotime Institute of Biotechnology) for $15 \mathrm{~min}$. The protein concentrations were determined using the BCA Protein Assay kit (Beyotime Institute of Biotechnology). Equal amounts of proteins (50 $\mu \mathrm{g}$ per condition) were incubated with Caspase-3/9 activities kits (C1115 or C1157; Beyotime Institute of Biotechnology) for $1-2 \mathrm{~h}$ at $37^{\circ} \mathrm{C}$. Absorbance was measured using a FluoDia T70 microplate reader (Photon Technology International, Inc.; Horiba, Ltd.) at a wavelength of $405 \mathrm{~nm}$ and analyzed using SPSS version 17.0 (SPSS, Inc., Chicago, IL, USA).

Western blot analysis. HK-1 cells were seeded $\left(1-2 \times 10^{5}\right.$ cells/well) into 6 -well plates, incubated overnight and treated with oxymatrine $(0,4,6$ and $8 \mathrm{mg} / \mathrm{ml})$ for 2 days. Protein extracts were prepared in RIPA for $15 \mathrm{~min}$. Protein concentrations were determined using the BCA Protein Assay kit (Beyotime Institute of Biotechnology). Equal amounts of proteins $(50 \mu \mathrm{g})$ were separated by $8-10 \%$ SDS-PAGE and transferred to polyvinyl difluoride membranes (EMD Millipore, Billerica, MA, USA). Membranes were blocked in PBS with 5\% skimmed milk powder for $1 \mathrm{~h}$ at $37^{\circ} \mathrm{C}$ and

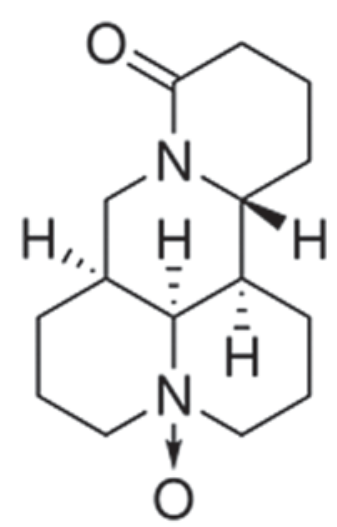

Figure 1. Chemical structure of oxymatrine.

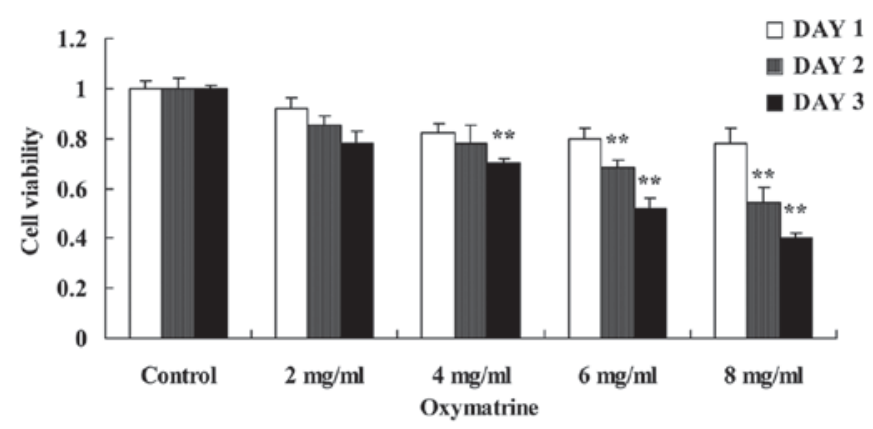

Figure 2. Oxymatrine inhibits cell proliferation in nasopharynx cancer HK-1 cells at various concentrations and lengths of exposure. ${ }^{* *} \mathrm{P}<0.01$ vs. untreated Control.

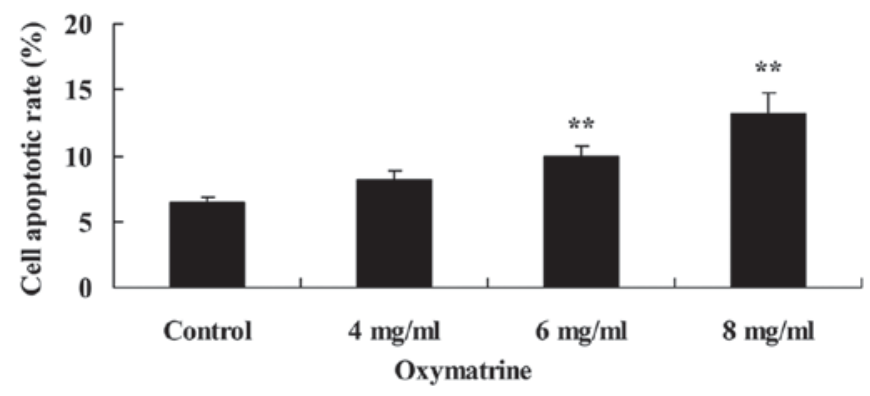

Figure 3. Oxymatrine induces apoptosis in nasopharynx cancer HK-1 cells at higher concentrations. ${ }^{* *} \mathrm{P}<0.01$ vs. untreated Control.

$0.1 \%$ Tween-20 and incubated with primary antibodies against p53 (sc-6243; 1:500; Santa Cruz Biotechnology, Inc., Dallas, TX, USA), Bax (sc-493; 1:500), cyclin D (sc-25764; 1:500), PI3K (sc-7174; 1:500), phosphorylated (p)-AKT (sc-135650; 1:500), p-mTOR p-p70S6K (sc-8416; 1:500), NF- $\mathrm{KB}$ (sc-109; 1:500) and GAPDH (sc-25778; 1:500; all from Santa Cruz Biotechnology, Inc., Dallas, TX, USA) overnight at $4^{\circ} \mathrm{C}$. Following washes with Tris-buffered saline and $0.1 \%$ Tween-20, membranes were incubated with horseradish peroxidase-conjugated anti-mouse or anti-rabbit secondary antibody (sc-2005 or sc-2004; 1:5,000; Santa Cruz Biotechnology, Inc.) for $1 \mathrm{~h}$ at $37^{\circ} \mathrm{C}$ and visualized using the Enhanced Chemiluminescence Detection reagent (BD Biosciences) and analyzed using ImageLab version 3.0 (BD Biosciences). 
A

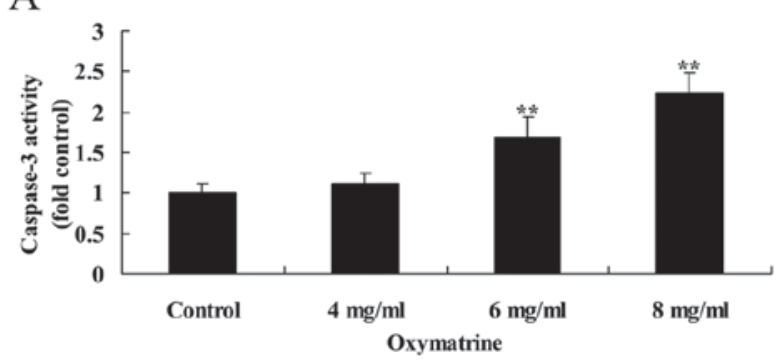

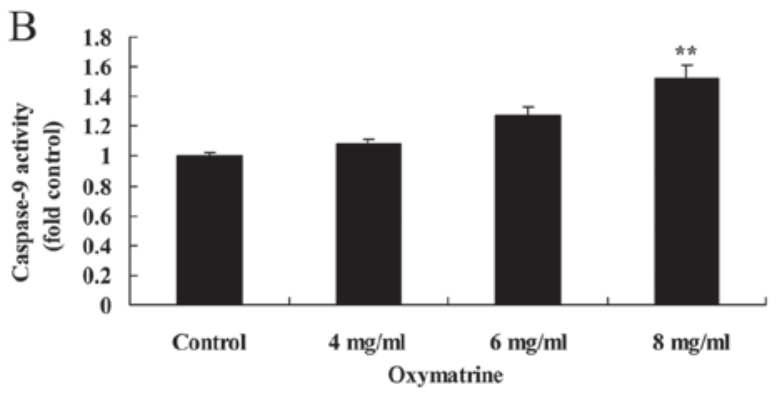

Figure 4. Oxymatrine induces the activity of caspase-3 and caspase-9 in nasopharynx cancer HK-1 cells. Oxymatrine treatment induced the activities of (A) caspase- 3 and (B) caspase- 9 at higher concentrations. ${ }^{* *} \mathrm{P}<0.01$ vs. untreated Control.
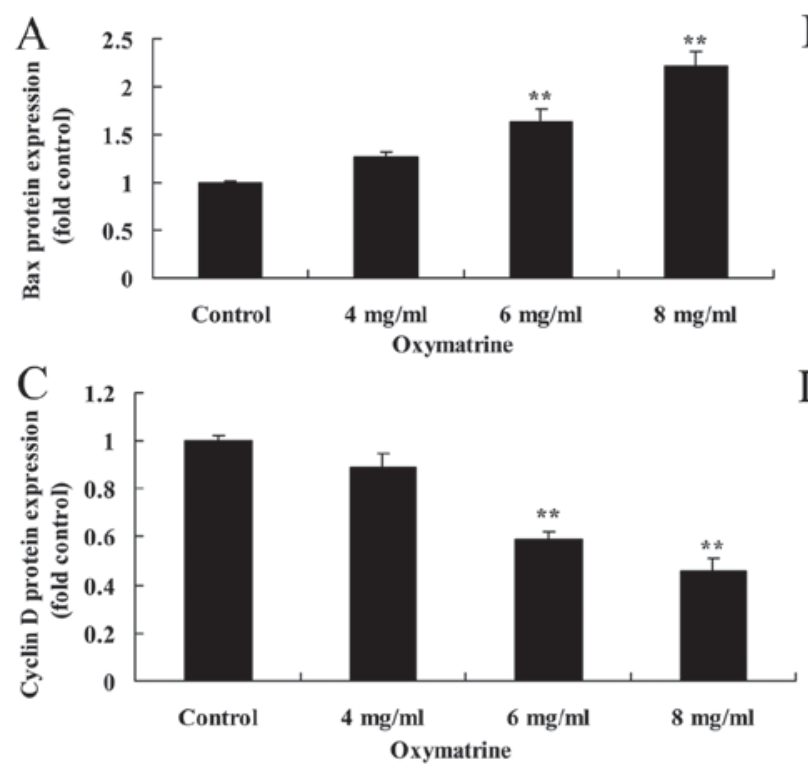

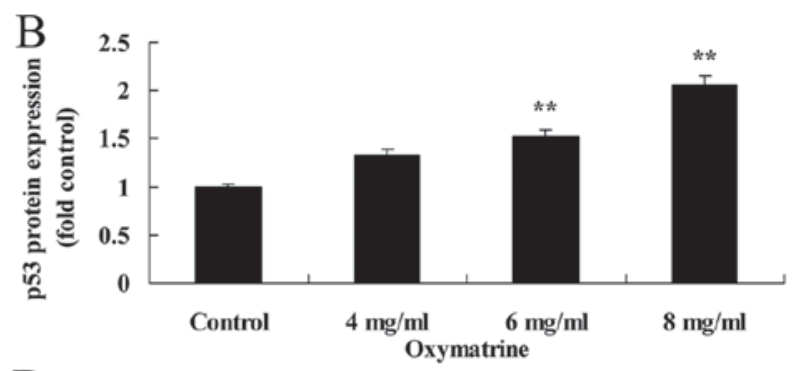

$\mathrm{D}$

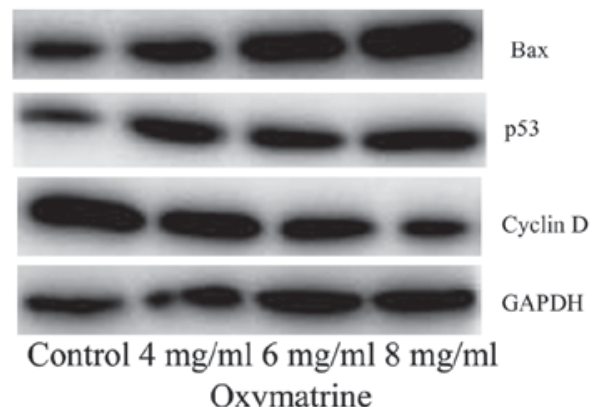

Figure 5. Oxymatrine affects the protein expression levels of Bax, p53 and cyclin D in nasopharynx cancer HK-1 cells. Oxymatrine treatment induced the protein expression of (A) Bax and (B) p53, and (C) reduced the expression of cyclin D. (D) Representative image of western blotting analysis used to draw the graphs in (A-C). ${ }^{* *} \mathrm{P}<0.01$ vs. untreated Control.

Statistical analysis. Data are expressed as the mean \pm standard deviation ( $\mathrm{n}=3)$, and statistical analysis was carried out using SPSS version 17.0 (SPSS, Inc.). Statistically significant differences between groups were determined by one-way analysis of variance and Tukey's post hoc test. $\mathrm{P}<0.05$ was considered to indicate a statistically significant difference.

\section{Results}

Oxymatrine inhibits NPC cell proliferation. To investigate the putative anticancer effects of oxymatrine on NPC cell growth, HK-1 cells were treated with various concentrations of oxymatrine. Results from the MTT assays suggested that oxymatrine inhibited cell proliferation of HK-1 cell in a timeand dose-dependent manner (Fig. 2). Treatment with 4, 6 and $8 \mathrm{mg} / \mathrm{ml}$ of oxymatrine significantly inhibited cell proliferation of HK-1 cells, compared with the untreated Control group (Fig. 2).

Oxymatrine induces NPC cell apoptosis. Oxymatrine-induced NPC cell apoptosis was measured using Annexin V-FITC/PI double staining. The results demonstrated that 6 and $8 \mathrm{mg} / \mathrm{ml}$ of oxymatrine treatment significantly induced NPC HK-1 cell apoptosis, compared with cells in the untreated Control group (Fig. 3).

Oxymatrine induces the activity of caspase- 3 and caspase- 9 in NPC cells. The effects of oxymatrine treatment on inducing the activities of caspase-3 and caspase-9 in NPC HK-1 cells were determined. Oxymatrine exposure increased the activities of both caspase-3 and caspase-9, compared with the Control group (Fig. 4).

Oxymatrine affects the protein expression levels of Bax, p53 and cyclin $D$ in NPC cells. The effects of oxymatrine on Bax, p53 and cyclin D protein expression of NPC HK-1 cells were examined. Compared with cells in the untreated Control group, oxymatrine treatment at 6 and $8 \mathrm{mg} / \mathrm{ml}$ significantly induced the protein expression of Bax and p53, and suppressed cyclin D protein expression (Fig. 5).

Oxymatrine suppressed the protein expression levels of PI3K, $p$-AKT and p-mTOR in NPC cells. To investigate the possible molecular mechanisms underlying oxymatrine-induced NPC 

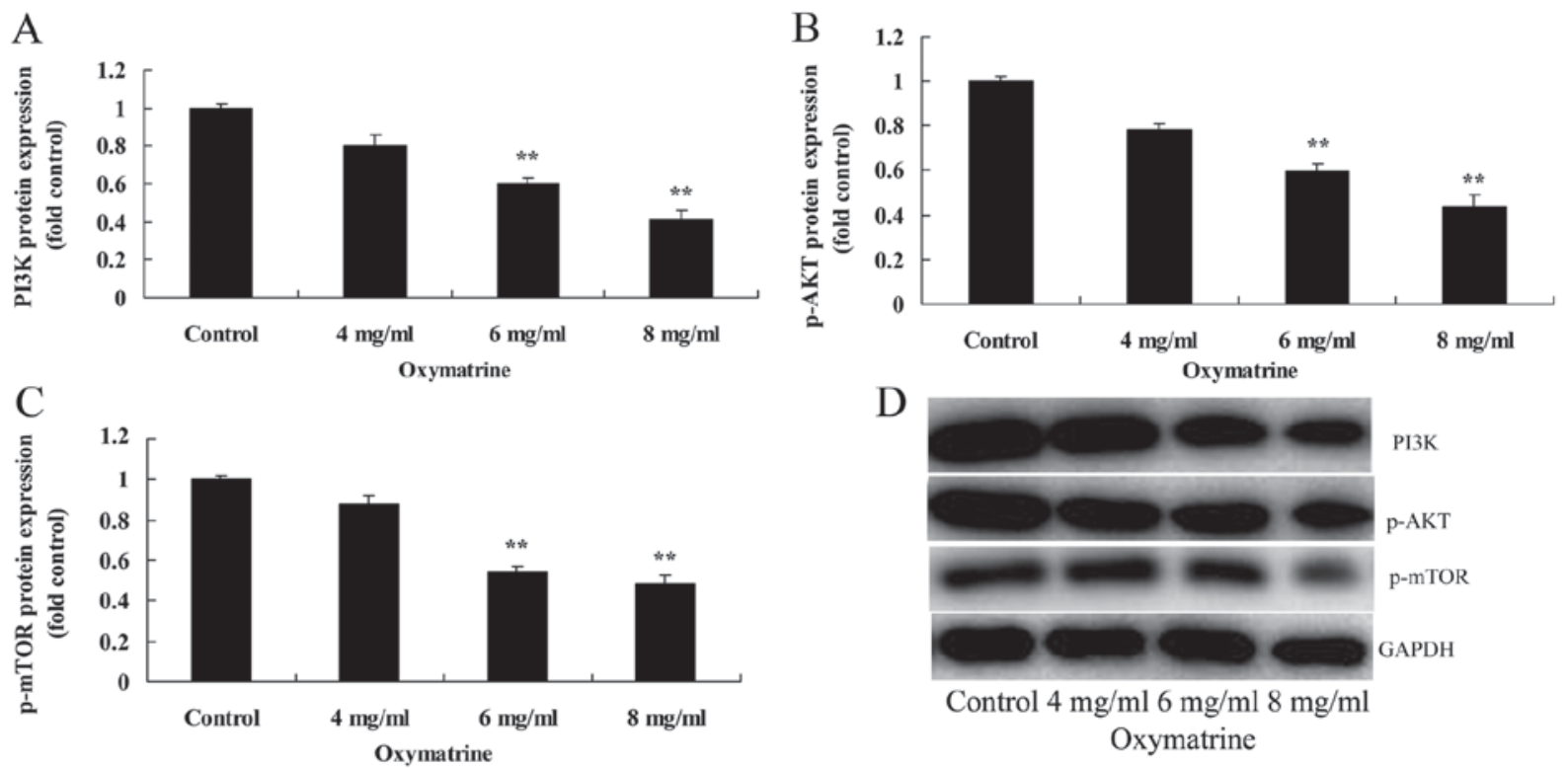

Figure 6. Oxymatrine suppresses the protein expression levels of PI3K, p-AKT and p-mTOR in nasopharynx cancer HK-1 cells. Oxymatrine treatment induced the protein expression of (A) PI3K, (B) p-AKT and (C) p-mTOR. (D) Representative image of western blotting analysis used to draw the graphs in (A-C). ${ }^{* *} \mathrm{P}<0.01$ vs. untreated Control. mTOR, mammalian target of rapamycin; $\mathrm{p}$, phosphorylated; PI3K, phosphoinositide 3 kinase.

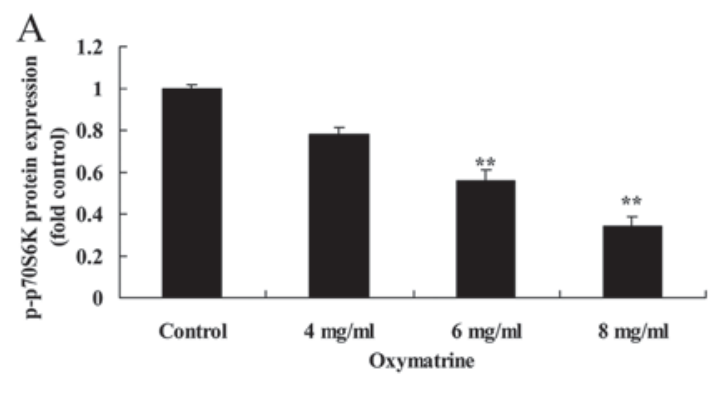

C

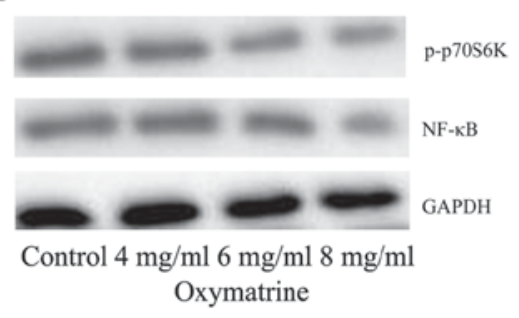

B

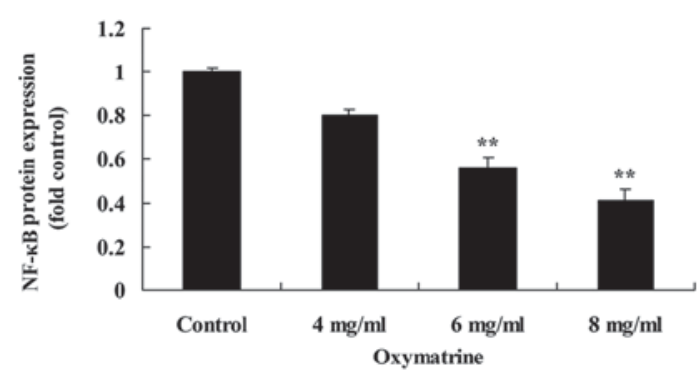

Figure 7. Oxymatrine suppresses the protein expression levels of p-p70S6K and NF- $\kappa B$ in nasopharynx cancer HK-1 cells. Oxymatrine treatment induced the protein expression of (A) p-p70S6K and (B) NF- $\mathrm{kB}$. (C) Representative image of western blotting analysis used to draw the graphs in $(\mathrm{A}$ and $\mathrm{B})$. ${ }^{* * *} \mathrm{P}<0.01$ vs. untreated Control. NF, nuclear factor; p, phosphorylated; p70S6K, p70 ribosomal protein S6 kinase.

cell apoptosis, PI3K/AKT signaling was analyzed following treatment with different concentrations of oxymatrine. Western blotting results suggested that oxymatrine treatment at 6 and $8 \mathrm{mg} / \mathrm{ml}$ significantly suppressed the protein expressions of PI3K, p-AKT and p-mTOR of HK-1 cell, compared with the Control group (Fig. 6).

Oxymatrine suppresses the protein expression levels of p-p70S6K and NF- $\kappa B$ in NPC cells. To further understand the role of p70S6K in oxymatrine-induced nasopharynx cancer cell apoptosis, $\mathrm{p}-\mathrm{p} 70 \mathrm{~S} 6 \mathrm{~K}$ and $\mathrm{NF}-\kappa \mathrm{B}$ protein expression levels were analyzed in NPC HK-1 cells treated with various concentrations of oxymatrine. Compared with cells in the untreated Control group, oxymatrine treatment at 6 and $8 \mathrm{mg} / \mathrm{ml}$ significantly suppressed the protein expression levels of p-p70S6K and NF- $\mathrm{B}$ (Fig. 7).

\section{Discussion}

NPC is a common malignant tumor in southern China, and is characterized by high racial susceptibility, regional aggregation and family tendency (13). The cause of NPC remains unknown, but it is currently considered to be related to genetic factors, environmental factors and viral infection (14). The 
clinical symptoms of NPC are complicated and diverse, are easy to be misdiagnosed or may by ignored by patients, and include clinical characteristics such as high degree of malignancy, early cervical lymph node metastasis and distant metastasis (15). Data from the present study demonstrated that oxymatrine treatment significantly inhibited cell proliferation and induced NPC cell apoptosis in HK-1 cells.

$\mathrm{Bcl} 2$ is an apoptosis-regulator that has been thoroughly studied, and its change in expression not only affects normal apoptosis of damaged DNA cells and abnormal cells, but also the apoptosis of tumor cells (16). Bcl2 proteins are highly expressed in NPC tissues and atypical hyperplasia epithelium, which suggested that $\mathrm{Bcl} 2$ proteins may serve an important role in the early stage of NPC, and the overexpression of $\mathrm{Bcl} 2$ may also be related to the inhibition of the apoptosis of NPC (17). The present study demonstrated that oxymatrine increased the expression levels of caspase- 3 and caspase- 9 and Bax protein expression of $\mathrm{HK}-1$ cell.

p53 has been reported to have at close relationship with human tumors, and functions to block cell cycle, inhibit cell proliferation, induce cell differentiation, initiate apoptosis and maintain the stability of genome (16). In the present study, higher concentrations of oxymatrine treatment (6 and $8 \mathrm{mg} / \mathrm{ml}$ ) significantly induced the protein expression of p53 in NPC HK-1 cells. A previous study suggested that oxymatrine inhibits prostate cancer cell proliferation through p53 and $\mathrm{Bax} / \mathrm{Bcl} 2$ expression (18).

Cyclin D1 (also known as Bcl-1) is encoded by CCND1, which is located on chromosome 11q13, comprises 5 exons and 4 introns, and is $15 \mathrm{~kb}$ long (19). Cyclin D1 is a nuclear protein that serves an important role in the regulation of the G1 stage of the cell cycle. Overexpression of cyclin D1 may lead to the disorder of regulation and detection point at $\mathrm{G} 1 / \mathrm{S}$ stage, thus accelerating cell cycle progression and inducing irreversible abnormal proliferation, which results in disordered cell proliferation and regulation (20). As a regulatory factor of cell cycle, cyclin D1 has a close relationship with cell proliferation, it participates in the regulation of cell cycle, and reflects proliferative activity of cells to a certain extent, and the proliferative activity of tumor cells is one of crucial factors affecting the radiosensitivity of NPC (21). Overall, the results of the present study suggested that oxymatrine significantly suppressed the protein expression of cyclin D of HK-1 cell. Another study reported that oxymatrine enhances the antitumor activity of oxaliplatin on colon cancer cell growth by downregulating cyclin $\mathrm{D}$ expression and the PI3K/AKT/mTOR pathway (22).

Previous studies have indicated that the biological function of the PI3K/AKT signaling pathway is closely related to the survival of tumor cells, glucose metabolism and the incidence and development of tumors $(5,23)$. There are extensive and in-depth studies on the effects of PI3K/AKT signaling in the occurrence and development, as well as resistance to radiotherapy, chemotherapy and drugs, of malignant tumors $(5,23)$. One previous study reported that AKT was highly expressed and the activity of AKT kinase was increased in ovarian cancer tissues, which was associated with the biological behaviors of malignant tumors (24). Other studies have demonstrated that the incidence and development of prostate cancer, cervical cancer, non-small cell lung cancer and other malignant tumors are closely related to the activation of the PI3K/AKT signaling pathway $(5,25)$. In the present study, oxymatrine treatment significantly reduced the protein expression levels of PI3K, p-AKT, p-mTOR and p-p70S6K in NPC HK-1 cells.

$\mathrm{NF}-\kappa \mathrm{B}$ belongs to a family of tumorigenesis proteins, and several functional proteins encoded by $N F-\kappa B$ may promote tumor growth (10). The cyclin D1 promoter region contains two $\mathrm{NF}-\kappa \mathrm{B}$ binding sites, and the activation of $\mathrm{NF}-\kappa \mathrm{B}$ promotes conversion function of the expression of cyclin D1 and G1/S, which accelerates cell cycle progression (26). NF- $\kappa \mathrm{B}$ may also promote tumorigenesis by inhibiting apoptosis (27). In vitro experiments demonstrated that specifically inhibiting the activity of NF- $\kappa \mathrm{B}$ was able to block the cell cycle in glioma cell lines and induce the apoptosis of tumor cells, whereas in vivo experiments confirmed that $\mathrm{NF}-\kappa \mathrm{B}$ inhibited the growth of glioma cells in rats (27). The results of the present study revealed that oxymatrine treatment suppressed the protein expression of $\mathrm{NF}-\kappa \mathrm{B}$ in NPC HK-1 cells. A previous study demonstrated that oxymatrine inhibited epithelial-mesenchymal transition of colorectal cancer cells through the regulation of $N F-\kappa B$ signaling (11).

In conclusion, the results of the present study demonstrated that oxymatrine significantly inhibited cell proliferation, induced NPC cell apoptosis, increased caspase-3 and caspase- 9 activities, promoted p53 and Bax protein expression and suppressed cyclin D protein expression in NPC HK-1 cells through the regulation of $\mathrm{PI} 3 \mathrm{~K} / \mathrm{AKT}$ and $\mathrm{NF}-\kappa \mathrm{B}$ pathway. Therefore, these findings may provide a novel approach for the development of oxymatrine, which is derived from TCM herb, as a potential NPC therapy.

\section{References}

1. Casanova M, Özyar E, Patte C, Orbach D, Ferrari A, Veyrat-Follet C, Errihani H, Pan J, Zhang L, Shen L, et al: International randomized phase 2 study on the addition of docetaxel to the combination of cisplatin and 5-fluorouracil in the induction treatment for nasopharyngeal carcinoma in children and adolescents. Cancer Chemother Pharmacol 77: 289-298, 2016.

2. Chen Y, Liu MZ, Liang SB, Zong JF, Mao YP, Tang LL, Guo Y, Lin AH, Zeng XF and Ma J: Preliminary results of a prospective randomized trial comparing concurrent chemoradiotherapy plus adjuvant chemotherapy with radiotherapy alone in patients with locoregionally advanced nasopharyngeal carcinoma in endemic regions of china. Int J Radiat Oncol Biol Phys 71: 1356-1364, 2008.

3. Li JG, Yuan X, Zhang LL, Tang YQ, Liu L, Chen XD, Gong XC, Wan GF, Liao YL, Ye JM and Ao F: A randomized clinical trial comparing prophylactic upper versus whole-neck irradiation in the treatment of patients with node-negative nasopharyngeal carcinoma. Cancer 119: 3170-3176, 2013.

4. Zhao M, Luo R, Liu Y, Gao L, Fu Z, Fu Q, Luo X, Chen Y, Deng X, Liang Z, et al: miR-3188 regulates nasopharyngeal carcinoma proliferation and chemosensitivity through a FOXO1-modulated positive feedback loop with mTOR-p-PI3K/AKT-c-JUN. Nat Commun 7: 11309, 2016.

5. Zheng D, Zhu G, Liao S, Yi W, Luo G, He J, Pei Z, Li G and Zhou Y: Dysregulation of the PI3K/Akt signaling pathway affects cell cycle and apoptosis of side population cells in nasopharyngeal carcinoma. Oncol Lett 10: 182-188, 2015.

6. Viana LR and Gomes-Marcondes MC: A leucine-rich diet modulates the tumor-induced down-regulation of the MAPK/ERK and $\mathrm{PI} 3 \mathrm{~K} / \mathrm{Akt} / \mathrm{mTOR}$ signaling pathways and maintains the expression of the ubiquitin-proteasome pathway in the placental tissue of NMRI mice. Biol Reprod 92: 49, 2015. 
7. Wong $\mathrm{CH}$, Loong $\mathrm{HH}$, Hui CW, Lau CP, Hui EP, Ma BB and Chan AT: Preclinical evaluation of the PI3K-mTOR dual inhibitor PF-04691502 as a novel therapeutic drug in nasopharyngeal carcinoma. Invest New Drugs 31: 1399-1408, 2013.

8. Tasioudi KE, Sakellariou S, Levidou G, Theodorou D, Michalopoulos NV, Patsouris E, Korkolopoulou P and Saetta AA: Immunohistochemical and molecular analysis of PI3K/AKT/mTOR pathway in esophageal carcinoma. APMIS 123: 639-647, 2015.

9. Shin SY, Kim CG, Jung YJ, Lim Y and Lee YH: The UPR inducer DPP23 inhibits the metastatic potential of MDA-MB-231 human breast cancer cells by targeting the Akt-IKK-NF- $\mathrm{BB}-\mathrm{MMP}-9$ axis. Sci Rep 6: 34134, 2016.

10. Zheng H, Dai W, Cheung AK, Ko JM, Kan R, Wong BW, Leong MM, Deng M, Kwok TC, Chan JY, et al: Whole-exome sequencing identifies multiple loss-of-function mutations of NF- $\kappa \mathrm{B}$ pathway regulators in nasopharyngeal carcinoma. Proc Natl Acad Sci USA 113: 11283-11288, 2016.

11. Liang L and Huang J: Oxymatrine inhibits epithelial-mesenchymal transition through regulation of NF- $\kappa \mathrm{B}$ signaling in colorectal cancer cells. Oncol Rep 36: 1333-1338, 2016.

12. Lin B, Li D and Zhang L: Oxymatrine mediates Bax and Bcl-2 expression in human breast cancer MCF-7 cells. Pharmazie 71 154-157, 2016

13. Peng PJ, Ou XQ, Chen ZB, Liao H, Peng YL, Wang SY, Zhang HY and Lin Z: Multicenter phase II study of capecitabine combined with nedaplatin for recurrent and metastatic nasopharyngeal carcinoma patients after failure of cisplatin-based chemotherapy. Cancer Chemother Pharmacol 72: 323-328, 2013.

14. Chen Y, Sun Y, Liang SB, Zong JF, Li WF, Chen M, Chen L, Mao YP, Tang LL, Guo Y, et al: Progress report of a randomized trial comparing long-term survival and late toxicity of concurrent chemoradiotherapy with adjuvant chemotherapy versus radiotherapy alone in patients with stage III to IVB nasopharyngeal carcinoma from endemic regions of China. Cancer 119: 2230-2238, 2013.

15. Zhang $\mathrm{Y}$, Zhao L, Huang $\mathrm{P}$, Wu J, Wang $\mathrm{F}$, Huang $\mathrm{Y}$ and Zhang L: Open-label, single-arm phase II study of pemetrexed in the treatment of patients with recurrent or metastatic nasopharyngeal carcinoma who have had prior platinum-based chemotherapy. Cancer Chemother Pharmacol 70: 611-615, 2012.

16. Bourouba M,Benyelles-Boufennara A,Terki N,Baraka-KerbouaE, Bouzid $\mathrm{K}$ and Touil-Boukoffa C: Epidermal growth factor receptor (EGFR) abundance correlates with p53 and Bcl-2 accumulation and patient age in a small cohort of North African nasopharyngeal carcinoma patients. Eur Cytokine Netw 22: 38-44, 2011.
17. Kao CL, Cho J, Lee YZ, Cheng YB, Chien CY, Hwang CF, Hong YR, Tseng CN and Cho CL: Ethanolic extracts of pluchea indica induce apoptosis and antiproliferation effects in human nasopharyngeal carcinoma cells. Molecules 20: 11508-11523, 2015.

18. Wu C, Huang W, Guo Y, Xia P, Sun X, Pan X and Hu W: Oxymatrine inhibits the proliferation of prostate cancer cells in vitro and in vivo. Mol Med Rep 11: 4129-4134, 2015.

19. Xu M, Cheung CC, Chow C, Lun SW, Cheung ST and Lo KW: Overexpression of PIN1 enhances cancer growth and aggressiveness with cyclin D1 induction in EBV-associated nasopharyngeal carcinoma. PLoS One 11: e0156833, 2016.

20. Liao D, Wu Y, Pu X, Chen H, Luo S, Li B, Ding C, Huang GL and He Z: Cyclin D1 G870A polymorphism and risk of nasopharyngeal carcinoma: A case-control study and meta-analysis. PLoS One 9: e113299, 2014.

21. Peng G, Cao RB, Li YH, Zou ZW, Huang J and Ding Q: Alterations of cell cycle control proteins SHP-1/2, p16, CDK4 and cyclin D1 in radioresistant nasopharyngeal carcinoma cells. Mol Med Rep 10: 1709-1716, 2014.

22. Liu Y, Bi T, Wang Z, Wu G, Qian L, Gao Q and Shen G: Oxymatrine synergistically enhances antitumor activity of oxaliplatin in colon carcinoma through $\mathrm{PI} 3 \mathrm{~K} / \mathrm{AKT} / \mathrm{mTOR}$ pathway. Apoptosis 21: 1398-1407, 2016.

23. Yu X, Zhen Y, Yang H, Wang H, Zhou Y, Wang E, Marincola FM, Mai C, Chen Y, Wei H, et al: Loss of connective tissue growth factor as an unfavorable prognosis factor activates miR-18b by $\mathrm{PI} 3 \mathrm{~K} / \mathrm{AKT} / \mathrm{C}-\mathrm{Jun}$ and C-Myc and promotes cell growth in nasopharyngeal carcinoma. Cell Death Dis 4: e634, 2013.

24. Yuen JW, Chung GT, Lun SW, Cheung CC, To KF and Lo KW: Epigenetic inactivation of inositol polyphosphate 4-phosphatase B (INPP4B), a regulator of PI3K/AKT signaling pathway in EBV-associated nasopharyngeal carcinoma. PLoS One 9: e105163, 2014.

25. Chen J: Roles of the PI3K/Akt pathway in Epstein-Barr virus-induced cancers and therapeutic implications. World J Virol 1: 154-161, 2012.

26. Zhu DD, Zhang J, Deng W, Yip YL, Lung HL, Tsang CM, Law WT, Yang J, Lau VM, Shuen WH, et al: Significance of $\mathrm{NF}-\kappa \mathrm{B}$ activation in immortalization of nasopharyngeal epithelial cells. Int J Cancer 138: 1175-1185, 2016.

27. Lin ML, Lu YC, Chung JG, Wang SG, Lin HT, Kang SE, Tang CH, Ko JL and Chen SS: Down-regulation of MMP-2 through the p38 MAPK-NF-kappaB-dependent pathway by aloe-emodin leads to inhibition of nasopharyngeal carcinoma cell invasion. Mol Carcinog 49: 783-797, 2010. 